\title{
CORRIGENDUM
}

\section{The golden anniversary of the thymus}

Jacques F. A. P. Miller

Nature Reviews Immunology 11, 489-495 (2011)

In the original version of this article, in the section under the title "Lymphocyte subsets" on page 491, a key reference was unintentionally omitted. At the end of the sentence "T cells that help B cells to produce antibody ( $T$ helper $\left(T_{H}\right)$ cells) generally bear the CD4 marker (originally known as L3T4), whereas those that serve cytotoxic functions (cytotoxic T lymphocytes (CTLs)) are usually characterized by the presence of CD8 molecules (originally known as LYT2 and

LYT3)" the following reference should have been cited: Kisielow, P. et al. Ly antigens as markers for functionally distinct subpopulations of thymus-derived lymphocytes of the mouse. Nature 253, 219-220 (1975). The author apologizes for this omission. 